\title{
E-Learning Berbasis Web Pada Sekolah SMK Rex Mundi Jakarta
}

\author{
Agus Salim ${ }^{1}$, Johanes Fernandes Andry ${ }^{2}$ \\ Program Studi Sistem Informasi, Fakultas Teknologi dan Desain, Universitas Bunda Mulia, Jakarta \\ Email: agusgunawan96@gmail.com, jandry@bundamulia.ac.id
}

\begin{abstract}
Abstrak - Penelitian ini bertujuan untuk membangun e-learning untuk SMK Rex Mundi Jakarta guna memenuhi dan mendukung proses kegiatan belajar mengajar yang ada selama ini. Aplikasi ini dibangun untuk memudahkan guru dan siswa dalam proses belajar mengajar yang tidak dibatasi oleh waktu dan ruang. Dimana terdapat banyak fitur-fitur di dalam aplikasi ini yang bertujuan sebagai sarana melakukan pengelolaan informasi bagi sekolah tersebut. Metode penelitian yang digunakan dalam pengumpulan data yaitu: observasi, studi kepustakaan dan wawancara dengan pihak stakeholder. Analisa dan perancangan website ini menggunakan diagram Unified Modelling Language (UML), dan Entitas Relationship Diagram (ERD) serta menggunakan metode System Development Life Cycle (SDLC) Waterfall dan menggunakan bahasa pemprograman HTML, PHP, CSS, JS dan MySQL sebagai database. Hasil yang diperoleh adalah aplikasi ini dapat mengelola nilai murid, jadwal kelas, pengumuman, dan report data murid dan guru sehingga dapat mengoptimalkan proses belajar di SMK Rex Mundi Jakarta. Aplikasi web e-learning dapat menjadi solusi dari masalah yang dihadapi oleh SMK Rex Mundi Jakarta. Aplikasi ini dapat dikembangkan menjadi lebih besar lagi sesuai dengan kebutuhan SMK Rex Mundi dimasa akan datang.
\end{abstract}

Kata kunci: E-Learning, UML, ERD, Waterfall, SMK Rex Mundi 


\section{PENDAHULUAN}

Sejalan dengan perkembangan kemajuan ilmu pengetahuan dan teknologi, banyak kegiatan pembelajaran yang dapat dilakukan dengan memanfaatkan teknologi informasi. Kehadiran teknologi informasi dalam bidang pendidikan khususnya dalam proses belajar mengajar sudah menjadi kebutuhan yang sangat penting diantaranya adalah dengan menerapkan e-learning berbasis web [1], [2].

Harta terpenting di dunia adalah data dan informasi, dan oleh karena itu penyimpanan data merupakan isu serius yang harus diperhatikan [3], [4]. Berarti untuk melakukan e-learning dan juga mengolah nilai, jadwal, pengumuman, kelas, data siswa dan guru, dll. Sebagian besar institusi atau sekolah sekarang memiliki perhatian yang lebih besar terhadap berbagai jenis kebutuhan bisnis [3], [5], [6]. Murid dalam hal ini adalah peserta didik dalam belajar tidak sekedar meniru dan membentuk bayangan dari apa yang diamati atau diajarkan guru, tetapi secara aktif ia menyeleksi, menyaring, memberi arti, dan menguji kebenaran atas informasi yang diterimanya [7]. Salah satu tujuan dan tantangan bagi dunia pendidikan di Indonesia adalah bagaimana menyediakan suatu sistem pendidikan yang dapat menampung besarnya peserta didik dan mampu melakukan akselerasi pendidikan dengan kualitas pendidikan yang baik bagi upaya untuk membentuk siswa seutuhnya yang kuat dan cerdas. Satu solusinya adalah melakukan proses pembelajaran mandiri atau pembelajaran jarak jauh dengan teknologi yang dikenal dengan e-learning [8].

Manfaat aplikasi e-Learning berbasis web diharapkan dapat mendukung proses pembelajaran siswa-siswi SMK Rex Mundi, Jakarta melalui online dan menimalisir penggunaan kertas di kelas. $E$ Learning ini memungkinkan siswa melakukan aktivitas pembelajaran melalui web kapan saja dan dimana saja sehingga mempermudahkan dalam penyebaran ilmu pengetahuan.

\section{TEORI E-LEARNING}

E-Learning adalah suatu sistem atau konsep pendidikan yang memanfaatkan teknologi informasi dalam proses belajar mengajar. Berikut beberapa pengertian e-learning dari berbagai sumber:

- Pembelajaran yang disusun dengan tujuan menggunakan sistem elektronik atau komputer sehingga mampu mendukung proses pembelajaran [9].

- Proses pembelajaran jarak jauh dengan menggabungkan prinsip-prinsip dalam proses pembelajaran dengan teknologi [10].

- Sistem pembelajaran yang digunakan sebagai sarana untuk proses belajar mengajar yang dilaksanakan tanpa harus bertatap muka secara langsung antara guru dengan siswa [11].

\section{METODE PELAKSANAAN}

Desain penelitian ini ditunjukkan pada Gambar 1. Pada gambar tersebut ditunjukkan gambaran metode pelaksanaan yang dirancang. Dengan melakukan perancangan sistem dengan metode System Development Life Cycle (SDLC) model Waterfall. SDLC merupakan siklus pengembangan sistem. Pengembangan sistem teknik (engineering system development). SDLC berfungsi untuk menggambarkan tahapan-tahapan utama dan langkah-langkah dari setiap tahapan yang secara garis besar terbagi dalam empat kegiatan utama, yaitu survei, analisis, desain, programming dan implementasi serta pemeliharaan. Tahapan pengembangan sistem digunakan untuk melakukan kegiatan dalam menyusun sebuah sistem yang akan dilakukan agar dapat mencapai hasil yang diinginkan. Sebab itu tahapan ini akan sangat bermanfaat bagi yang sedang melakukan pengembangan sistem.

Requirement atau analisis, Permodelan ini diawali dengan mencari kebutuhan dari keseluruhan sistem yang akan diaplikasikan ke dalam bentuk software. Hal ini sangat penting, mengingat software harus dapat berinteraksi dengan elemen-elemen yang lain seperti hardware, database, dsb. Analisis, ialah studi domain masalah bisnis untuk merekomendasikan perbaikan dan menspesifikasikan persyaratan dan prioritas bisnis untuk solusi. Analisis system ditujukan untuk menyediakan tim proyek dengan pemahaman yang lebih menyeluruh terhadap masalah-masalah dan kebutuhan-kebutuhan yang memicu proyek.

Desain adalah spesifikasi atau konstruksi solusi yang teknis dan berbasis komputer untuk persyaratan bisnis yang diidentifikasikan dalam analisis sistem. Selama desain sistem, pada awalnya akan mengekspolarasi solusi teknis alternatif. Setelah alternatif solusi disetujui, fase desain sistem mengembangkan cetak biru dan spesifikasi teknis yang dibutuhkan untuk mengimplementasikan database, program, antar muka pengguna yang dibutuhkan untuk aplikasi.

Coding atau pengkodean, Desain yang telah dibuat kemudian diubah bentuknya menjadi bentuk yang dapat dimengerti oleh mesin, yaitu ke dalam bahasa pemrograman melalui proses coding. Tahap ini merupakan implementasi dari tahap design yang secara teknis nantinya dikerjakan oleh programmer.

Testing adalah proses pengujian aplikasi dengan menggunakan black box dari sisi fungsi dengan menggunakan UAT (user acceptance test) dan implementasi, ialah konstruksi, instalasi, pengujian dan pengiriman sistem ke dalam produksi (artinya operasi sehari-hari). Implementasi sistem mengontruksi sistem informasi baru dan menempatkannya ke dalam operasi, selanjutnya dilaksanakan pengujian.

Maintenance atau pemeliharaan, suatu software diperlukan, termasuk di dalamnya adalah pengembangan, karena software yang dibuat tidak selamanya hanya seperti itu. Ketika dijalankan mungkin saja masih ada errors kecil yang tidak ditemukan sebelumnya, atau ada penambahan fiturfitur yang belum ada pada software tersebut. Pengembangan diperlukan ketika adanya perubahan dari eksternal perusahaan seperti ketika ada pergantian sistem operasi, atau perangkat lainnya. 


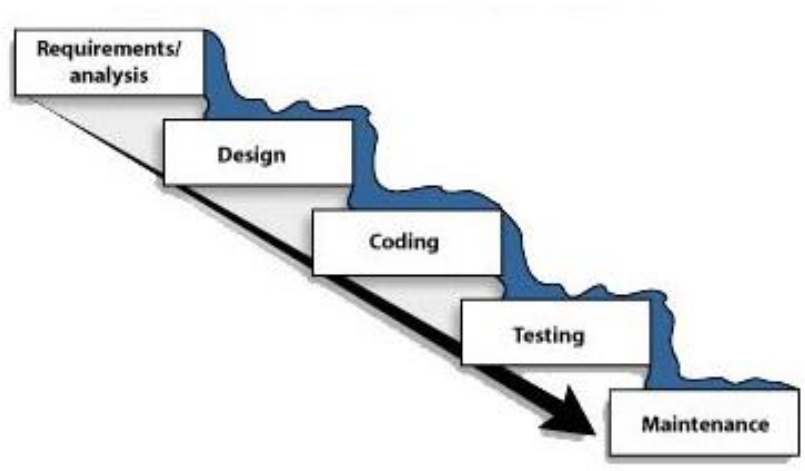

Gambar 1. SDLC Waterfall

\section{HASIL PELAKSANAAN}

A. Rekomendasi Kebutuhan Sistem

Kebutuhan yang diperlukan adalah sebuah wadah atau sarana yang mendukung proses penyebaran informasi dan pembelajaran yang terkait dalam pendidikan seperti, informasi pengumuman, forum diskusi dua arah, jadwal dan materi pelajaran. Dibutuhkan pula wadah untuk proses belajar mengajar yang dapat diakses dimana saja dan kapan saja, yang tidak mengharuskan untuk bertemu secara langsung atau bertatap muka.

Terdapat beberapa masalah yang sering terjadi seperti, penyebaran pengumuman melalui secarik kertas sering menjadi kendala ketika kertas surat tersebut dihilangkan oleh siswa. Akibatnya, siswa tidak dapat mengetahui apa informasi yang ada pada surat tersebut akibatnya anak murid tidak bisa memberikan informasi pengumuman tersebut kepada orang tuanya. Kesalahan jadwal sering terjadi pada anak murid karena jadwal hilang. Penyampaian materi pembelajaran yang diberikan guru kepada siswa hanya bisa dilakukan secara tatap muka dengan waktu yang telah ditentukan dan terbatas. Alhasil sering kali penyampaian materi tersebut tidak tersalurkan dengan baik dengan alasan waktu yang terbatas.

Berdasarkan kebutuhan dan masalah yang telah dijabarkan sebelumnya, maka diusulkan untuk membuat aplikasi e-learning yang dapat mendukung proses diskusi di luar jam sekolah, menyediakan informasi pengumuman, dan menyediakan wadah untuk para guru dalam memberikan tugas/kuis online kepada para siswa. Ditambahkan juga kemampuan untuk mengolah data guru dan murid, nilai, materi pelajaran jadwal, dan pengumuman. Dengan adanya aplikasi ini maka diharapkan dapat memberikan informasi yang lebih lengkap dan dapat diakses dengan mudah oleh siswa, guru maupun bagian administrasi atau tata usaha.

\section{B. Perancangan yang Diusulkan}

Analisis dengan use case diagram, Fase analisis adalah tahap untuk memahami detail dari kebutuhan bisnis dan reqirement. Alat dan teknik untuk analisis adalah UML. UML adalah standar bahasa pemodelan umum di bidang ilmu komputer dan rekayasa perangkat lunak. Standar ini dikelola dan dibuat oleh object management group [12]. Use case merupakan bagian utama dari fungsi sistem dan aktor adalah orang atau sistem yang berasal manfaat dari dan eksternal untuk subjek [13].

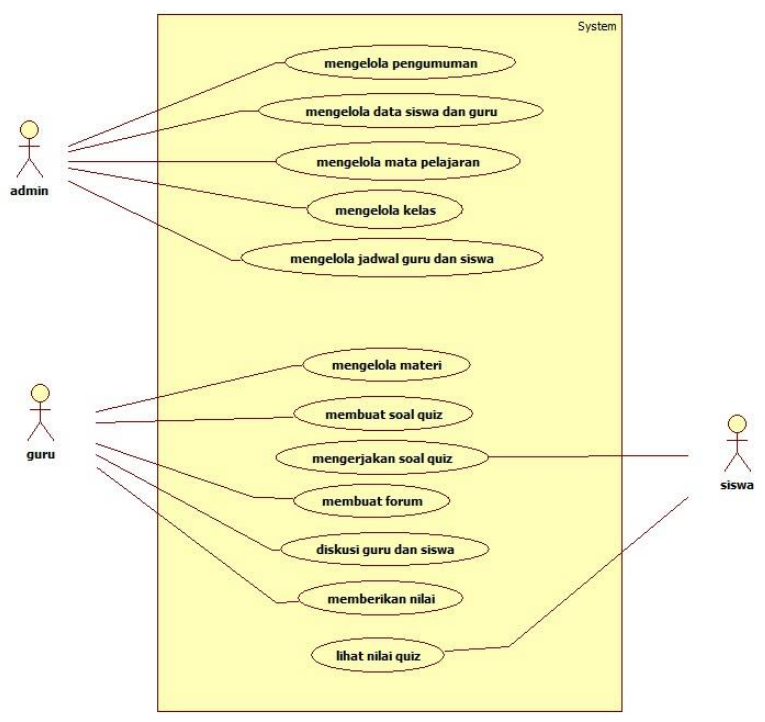

Gambar 2. Use Case Diagram SMK Rex Mundi

Gambar 2 menggambarkan bagaimana masingmasing aktor memiliki hak yang berbeda-beda. Hak akses sebagai admin, dapat mengelola pengumuman, mengelola data guru dan siswa, mengelola mata pelajaran, mengelola kelas dan mengelola jadwal guru dan siswa. Hak akses sebagai guru, dapat mengelola materi, membuat soal kuis, membuat forum, berdiskusi dengan siswa. Hak akses sebagai siswa, dapat mengerjakan soal kuis, berdiskusi dan melihat nilai. Perancangan untuk e-learning ini hanya menggunakan use case diagram, dikarenakan keterbatasan halaman.

Desain database adalah kumpulan terintegrasi dari elemen data yang secara logika saling berhubungan. Database mengonsolidasikan berbagai catatan yang dahulu disimpan dalam file-file terpisah ke dalam satu gabungan umum elemen data yang menyediakan data untuk e-learning. 


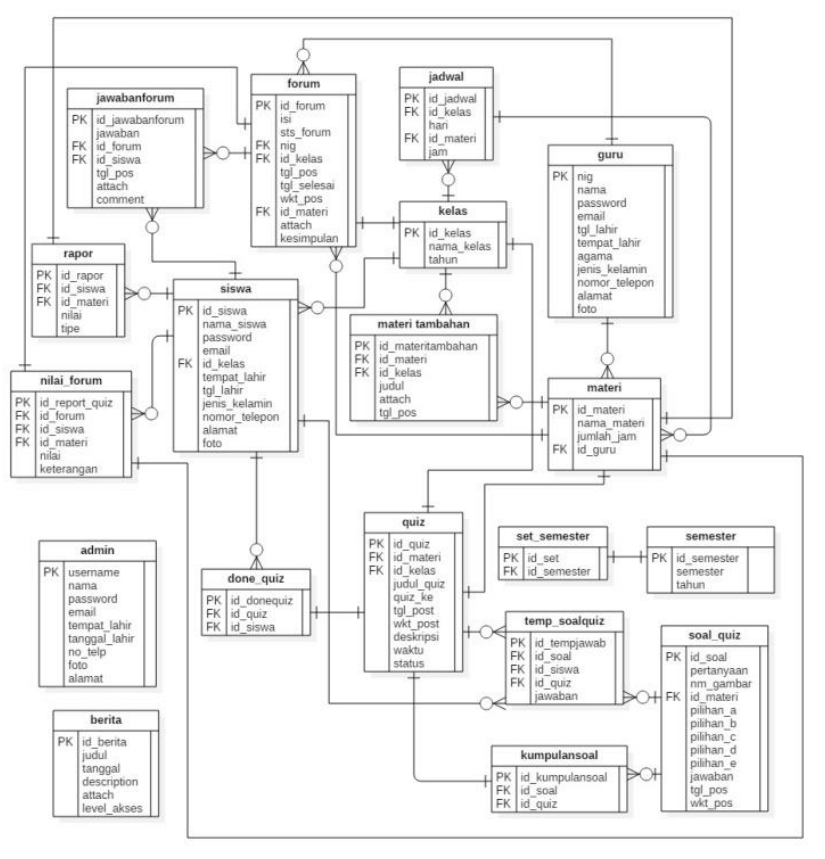

Gambar 3. Entity Relationship Diagram E-Learning

Gambar 3 merupakan gambaran secara utuh Entity Relationship Diagram (ERD) dari aplikasi E-learning ini. ERD digunakan untuk menggambarkan hubungan relasi antara entitas yang terdapat dalam suatu basis data.

Untuk melaksanakan coding dilakukan dengan bahasa pemprograman yang dilakukan dengan menggunakan PHP. PHP adalah bahasa pemrograman web server-side yang bersifat open source. PHP merupakan script yang terintegrasi dengan HTML dan berada pada server (server side HTML embedded scripting). PHP adalah script yang digunakan untuk membuat halaman website yang dinamis. Dinamis berarti halaman yang akan ditampilkan dibuat saat halaman itu diminta oleh client. Mekanisme ini menyebabkan informasi yang diterima client selalu yang terbaru atau up to date. Semua script PHP dieksekusi pada server di mana script tersebut dijalankan. Karena codingnya begitu banyak tidak bisa ditampilkan pada paper ini.

Testing atau pengujian adalah proses menjalankan atau eksekusi suatu program dengan tujuan utama untuk mencari/menemukan kesalahan (error) [14]. Dengan kata sederhana, pengujian perangkat lunak adalah kegiatan untuk memeriksa apakah hasil aktual sesuai dengan hasil yang diharapkan dan untuk memastikan bahwa aplikasi bebas cacat. pengujian dilakukan setelah aplikasi selesai dibuat, dengan metode black box testing. Pengujian dilakukan dengan User Acceptance Testing (UAT), dimana hasil keluaran dari tahap ini adalah scenario UAT. Pengujian dilakukan untuk mengetahui dan mengindentifikasi kesalahan yang mungkin terjadi [15]. Hasil UAT diperlihatkan pada Tabel 1.

Tabel 1. Pengujian Admin

\begin{tabular}{llll}
\hline No & Test Case & Hasil yang di & Sim- \\
\hline
\end{tabular}

\begin{tabular}{|c|c|c|c|}
\hline & & harapkan & $\begin{array}{l}\text { pula } \\
\mathrm{n}\end{array}$ \\
\hline 1 & $\begin{array}{l}\text { Username :- } \\
\text { Password : - }\end{array}$ & $\begin{array}{l}\text { Sistem akan menolak } \\
\text { akses dan muncul } \\
\text { pesan: " Please fill out } \\
\text { this field" }\end{array}$ & Valid \\
\hline 2 & $\begin{array}{l}\text { Username: } \\
\text { admin } \\
\text { Password: } \\
\text { - }\end{array}$ & $\begin{array}{l}\text { Sistem akan menolak } \\
\text { akses dan muncul } \\
\text { pesan: " Please fill out } \\
\text { this field" }\end{array}$ & Valid \\
\hline 3 & $\begin{array}{l}\text { Username : - } \\
\text { Password: } \\
\text { a }\end{array}$ & $\begin{array}{l}\text { Sistem akan menolak } \\
\text { akses dan muncul } \\
\text { pesan: "Please fill out } \\
\text { this field" }\end{array}$ & Valid \\
\hline 4 & $\begin{array}{l}\text { Username : } \\
\text { admin } \\
\text { Password: } \\
\text { a }\end{array}$ & $\begin{array}{l}\text { Sistem akan } \\
\text { menampilkan pesan : } \\
\text { "Tambah siswa telah } \\
\text { berhasil" }\end{array}$ & Valid \\
\hline 5 & $\begin{array}{l}\text { Mengisi data } \\
\text { siswa secara } \\
\text { lengkap dan } \\
\text { benar lalu } \\
\text { klik button } \\
\text { tambah }\end{array}$ & $\begin{array}{l}\text { Sistem akan } \\
\text { menampilkan pesan : } \\
\text { "Tambah siswa telah } \\
\text { berhasil" }\end{array}$ & Valid \\
\hline 6 & $\begin{array}{l}\text { Edit data } \\
\text { siswa secara } \\
\text { lengkap dan } \\
\text { benar lalu } \\
\text { klik button } \\
\text { simpan }\end{array}$ & $\begin{array}{l}\text { Sistem akan } \\
\text { menampilkan pesan : } \\
\text { "Edit siswa telah } \\
\text { berhasil" }\end{array}$ & Valid \\
\hline 7 & $\begin{array}{l}\text { Hapus data } \\
\text { siswa } \\
\text { dengan klik } \\
\text { button " } \\
\text { hapus" }\end{array}$ & $\begin{array}{l}\text { Sistem akan } \\
\text { menampilkan pesan : “ } \\
\text { hapus data siswa telah } \\
\text { berhasil” }\end{array}$ & Valid \\
\hline 8 & $\begin{array}{l}\text { Mengisi data } \\
\text { guru secara } \\
\text { lengkap dan } \\
\text { benar lalu } \\
\text { klik button } \\
\text { tambah }\end{array}$ & $\begin{array}{l}\text { Sistem akan menerima } \\
\text { dan muncul pesan : } \\
\text { "Tambah guru telah } \\
\text { berhasil" }\end{array}$ & Valid \\
\hline
\end{tabular}

\section{DAFTAR PUSTAKA}

[1] S. Kosasih, Perancangan E-Learning Untuk Meningkatkan Motivasi Belajar Guru dan Siswa, Prosiding Seminar Nasional Pendidikan Teknik Informatika (SENAPATI), ISSN: 2087-2658, 2015, pp. 82-88.

[2] S. K. Jirasak, N. T. Onjaree, K. Jantavee, Elements and Steps of E-Learning Benchmarking Model for Higher Education, Jurnal of Computer and Communications, vol. 2, 2014, pp. 37-41.

[3] J. F. Andry and Honni, Using Backup and Restore Automation from Disaster in Information Systems University, 2nd International Conference on Innovative Research Across Disciplines (ICIRAD 2017). ISBN: 978-94-6252-376-0, Published by Atlantis Press, scientific publishing, Paris, France, 2017, pp. 1-5.

[4] E. Wijaya, Robet and Robin, Perancangan Sistem Otomatisasi Backup Data Menggunakan File Transfer Protocol Berbasis Jaringan LAN (Studi Kasus Pada STMIK TIME Medan)," Jurnal TIMES, vol. IV, no. 1, 2015, pp. 26-30, ISSN: 2337-3601.

[5] L. L. Hoong and G. Marthandan, Critical Dimensions of Disaster Recovery Planning, International Journal of Business and Management, vol. 9, no. 12, 2014, ISSN 1833-3850, E-ISSN 1833-8119, Published by Canadian Center of Science and Education, pp. 145-158. 
[6] M. Gallangher, "Business Continuity Management How to protect your company from danger. Retrieved, 2003.http://pqm-online.com/assets/files/lib/gallagher.pdf

[7] M. Yazdi, E-Learning Sebagai Media Pembelajaran Interaktif Berbasis Teknologi Informasi, Jurnal IImiah Foristek, 2012, vol. 2, no. 1, pp. 143-152.

[8] Silahuddin, Penerapan E-Learning dalam Inovasi Pendidikan, Jurnal IImiah CIRCUIT, vol. 1 no. 1, 2015, pp. 48-59.

[9] M. Allen's Guide to e-Learning: Building Interactive, Fun, and Effective Learning Programs for Any Company, 2nd Edition, 2016, ISBN: 978-1-119-046325 , John Wiley \& Sons.

[10] S. R. Chandrawati, Pemamfaatan E-Learning Dalam Pembelajaran, Jurnal Cakrawala Kependidikan, vol. 8, no.2, 2010.

[11] I. Ardiansyah, Eksplorasi Pola Komunikasi dalam Diskusi Menggunakan Moddle pada Perkuliahan Simulasi Pembelajaran Kimia, 2013 Bandung: Universitas Pendidikan Indonesia.

[12] J. F. Andry, H. Agung, and Y. Erlyana, Management Information System for Order Fulfillment: A Case Study, 2016, Proceeding of 9th International Seminar on Industrial Engineering and Management, ISSN : 1978774X.

[13] A. Dennis, B. H. Wixom, Roth and M. Roberta, System Analysis and Design, fifth edition, 2012, John Wiley \& Sons, Inc.

[14] J. F. Andry, Pengembangan Aplikasi Backup Dan Restore Secara Automatisasi Menggunakan SDLC Untuk Mencegah Bencana, Jurnal Muara Sains, Teknologi, Kedokteran, dan IImu Kesehatan, 2017, vol. 1, no. 1, pp. 29-38.

[15] G. Saini, and K. Rai, An Analysis on Objectives, Importance and Types of Software Testing, 2013, International Journal of Computer Science and Mobile

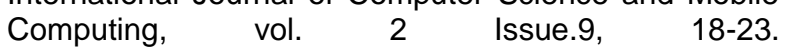

